\title{
Impact of Nutritional Counseling in Reducing Serum Cholesterol in Public Health Service Patients
}

\author{
Maria da Conceição Rosado Batista, Sylvia do Carmo Castro Franceschini
}

Viçosa, MG - Brazil

\begin{abstract}
Objective - To assess the impact of nutritional attention on the lipid profile and nutritional status of hypercholesterolemic patients attended in health centers of Belo Horizonte.
\end{abstract}

Methods - Using nutritional attendance patient record cards from two health units, the evolution of the lipid profile and the nutritional state (BMI) was monitored of 96 hypercholesterolemic patients who received diet. The patients were appraised at the following moments: initial ( $1^{\text {st }}$ consultation), after 3 months $\left(2^{\text {nd }}\right.$ consultation) and last consultation (variable for each patient).

Results - On the first attendance, 44,4\% of the patients presented not only high total cholesterol and $L D L-c$, but also hypertriglyceridemia and $70.3 \%$ were overweight or obese, but most patients $(75.6 \%)$ presented adequate HDL-c levels. There was significant reduction in the BMI, total cholesterol, $L D L$-c values $(p<0.01)$ and also in the triglyceride levels $(p<0.05)$ in the first three months, without alteration in the HDL-c levels. A significant reduction $(p<0.01)$ was observed in the frequency of individuals with high cholesterol (from $89.6 \%$ down to $47.9 \%$ ), high and very high $L D L-c$ (from $82.6 \%$ down to $45.7 \%$ ), as well as high and very high triglyceride (from $43.6 \%$ down to $16.7 \%$ ). The observed reduction in frequency of the low HDL-c was statistically meaningless.

Conclusion - This study evidences the effect of the nutritional attention on lipid profile in hypercholesterolemic patients, reinforcing the need for a multiprofessional team to attend them at the public health services.

Keywords: hypercholesterolemia, nutritional status, diet

Universidade Federal de Viçosa (UFV)

Mailing address: Correspondência: Sylvia do Carmo Castro Franceschini - Depto. de Nutrição e Saúde - Universidade Federal de Viçosa - Campus Universitário 36571-000 - Viçosa, MG - E-mail: sylvia@mail.ufv.br
Cardiovascular diseases account for $34 \%$ of deaths in Brazil, $11.6 \%$ of cerebrovascular disease, $9.8 \%$ of ischemic heart disease, $2.3 \%$ of arterial hypertension, and $10.3 \%$ of other cardiovascular causes ${ }^{1}$.

Dyslipidemias are among the most important risk factors for arteriosclerotic cardiovascular disease, together with hypertension, obesity, and diabetes mellitus ${ }^{2,3}$. However, national and international studies show that coronary events are reduced when intervention is made on multiple risk factors ${ }^{4,5}$.

Total cholesterol and LDL-c (Low-Density Lipoprotein Cholesterol) have a direct relationship with mortality and morbidity from coronary artery disease. Isolated hypertriglyceridemia is not an independent risk factor for coronary disease but becomes one when associated with high LDL-c levels and low HDL-c (Higher-Density Lipoprotein Cholesterol) levels ${ }^{6}$. HDL-c acts in the reverse transport of cholesterol, decreasing or reducing the formation of atherosclerotic plaque $^{3,6}$. In the third National Health and Nutrition Examination Study (NHANES III) ${ }^{7}$, held in the United States, many factors were reported to affect serum cholesterol levels, including age, diet, genetic predisposition, and body weight.

Few Brazilian studies investigate the effects of dietary intervention on the lipid profile of hypercholesterolemic individuals ${ }^{8}$. This study was carried out to assess the impact of nutritional counseling on the lipid profiles of hypercholesterolemic patients treated at basic health units on the outskirts of Belo Horizonte and to assess patients' nutritional status before and after this intervention.

\section{Methods}

Patients with hypercholesterolemia, referred by health care professionals for nutritional guidance, were studied at 2 basic health units on the outskirts of Belo Horizonte.

Data were collected on nutritional counseling record forms of patients treated from 1994 to 1999 , and the same nutritionist followed up and gave dietary advice.

During dietary counseling, the patient received instructions for food selection and portion size as well as food 
preparation techniques. The instructions were provided after a dietary recall and basically consisted of adjusting total fat consumption, reducing saturated fat, cholesterol, and transfatty acids, and increasing fiber, mainly the soluble ones (fruits and vegetables), according to the National Cholesterol Education Program (NCEP - 1993) ${ }^{9}$.

The dietary prescriptions were individualized according to patient's needs, and those excessively overweight patients were prescribed a low-fat diet while those with altered triglyceride levels were told to avoid the ingestion of simple sugar and alcoholic beverages.

Ninety-six patients were selected according to the following criteria: over 20 years of age, with total serum cholesterol $\geq 200 \mathrm{mg} / \mathrm{dL}$ (borderline or high), had received dietary counseling and returned at least once to consult with the nutritionist and had not used lipid-lowering medication during the study period. Diabetic patients and those with coronary artery disease were excluded so that the individuals could be assessed for primary prevention.

The number of participants by sex was $83(86.5 \%)$ females and $13(13.5 \%)$ males. The average age at the first screening was $53.2 \pm 12$ years, $68.8 \%$ up to 59 years and $31.3 \%$ over 60 .

The patients were weighed and measured by the same professional, on scales with an anthropometer, platform type, with a $150 \mathrm{~kg}$ capacity and $100 \mathrm{~g}$ precision.

The biochemical tests were carried out at municipal or licensed laboratories, and blood was collected after a 12hour fast.

Nutritional status was defined by body mass index (BMI), and the individual classified according to the World Health Organization (WHO, 1998) ${ }^{10}$ as low weight (BMI < 18.5), normal weight (18.5-24.9), pre-obese or overweight (25-29.9) obesity class I (30-34.9), obesity class II (35-39.9), and obesity class III $(\geq 40)$. BMI greater than 27 was considered a risk factor regardless of coronary disease ${ }^{11}$.

The reference levels of the serum lipids were defined according to the guidelines of the Brazilian Cardiology Society ${ }^{12}$, that is: optimum cholesterol $(<200 \mathrm{mg} / \mathrm{dL})$, borderline cholesterol (200-239mg/dL), high cholesterol ( $\geq$ $240 \mathrm{mg} / \mathrm{dL})$, optimum LDL-c ( $<100 \mathrm{mg} / \mathrm{dL})$, desirable LDL-c (100-129mg/dL), borderline LDL-c (130-159mg/dL), high LDL-c (160-189mg/dL), very high LDL-c $(\geq 190 \mathrm{mg} / \mathrm{dL})$, low HDL-c (<40mg/dL), high HDL-c ( $>60 \mathrm{mg} / \mathrm{dL})$, optimum triglycerides $(<150 \mathrm{mg} / \mathrm{dL})$, borderline triglycerides (150$200 \mathrm{mg} / \mathrm{dL}$ ), high triglycerides (200-499mg/dL), and very high triglycerides $(\geq 500 \mathrm{mg} / \mathrm{dL})$.
Castelli risk indices I and II (total cholesterol/HDL-c ratio and LDL-c/HDL-c ratio) were defined as low risk for men (cholesterol/HDL-c $\leq 5.1$ and LDL-c/HDL-c $\leq 3.3$ ), low risk for women (cholesterol/HDL-c $\leq 4.4$ and LDL-c/HDL-c $\leq$ 2.9), high risk for men (cholesterol/HDL-c $>5.8$ and LDL-c/ HDL-c > 3.8) and high risk for women (cholesterol/HDL-c > 5.3 and LDL-c/HDL-c $>3.5)^{13,14}$.

Because the data were collected from routine patient records at a basic health care center, the sample size was different for each variable. The time interval between the appointments was not regular either, because many patients did not return for screening during the established period.

The median time intervals between appointments were first screening (first consultation), - second screening (3 months after first screening) and the last screening (median of 11 months after the $1^{\text {st }}$ screening).

The data were processed with the EPI-INFO program, version $6.04{ }^{15}$. The median values, obtained at the first and second screenings were compared with the SIGMA STAT program ${ }^{16}$, by using the Wilcoxon test. To compare the frequencies observed before and after intervention, within each reference range of the serum lipids, the chi-square test was used, by adopting a $p<0.05$ as significance level.

\section{Results}

Table I presents the BMI, total cholesterol, HDL-c, LDL-c, triglycerides and Castelli I and II indices values on the first occasion of nutritional counseling. There were high mean and median values for BMI, total cholesterol, LDL-c and Castelli I and II indices. Both the mean and median were within the recommended level for HDL-c $(\geq 40$ $\mathrm{mg} / \mathrm{dL}$ ). But for triglycerides, the mean was high and the median was within the desirable value $(\leq 200 \mathrm{mg} / \mathrm{dL})$, due to great variability among the data.

Table II shows the results of the nutritional assessment by BMI of the hypercholesterolemic individuals on the first screening. Most of the hypercholesterolemic patients (70.3\%) were overweight or obese when they sought treatment to control their cholesterol.

By comparing the BMI at the first and last screening, a decrease from $31.9 \%$ to $19.8 \%$ was observed in the frequency of obesity (class I and II), although this difference was not statistically significant $(\mathrm{p}=0.06)$.

When the patients were separated into 2 groups (BMI $>27$ and BMI $\leq 27$ ), the group that had the greatest BMI

\begin{tabular}{|c|c|c|c|c|c|}
\hline Indexes & $\mathrm{N}$ & $\mathrm{X} \pm \mathrm{SD}$ & Minimum & Median & Maximum \\
\hline BMI & 91 & $27.7 \pm 4.29$ & 19 & 27.7 & 37.7 \\
\hline Total Cholesterol & 96 & $272 \pm 35.1$ & 211 & 263.5 & 369 \\
\hline HDL-c & 48 & $45.8 \pm 9.5$ & 21 & 46 & 67 \\
\hline LDL-c & 46 & $182 \pm 29.9$ & 127 & 176 & 267 \\
\hline Triglycerides & 81 & $206.5 \pm 137.4$ & 50 & 182 & 881 \\
\hline Cholest./HDL-c ratio & 46 & $5.99 \pm 1.53$ & 3.7 & 5.75 & 11.2 \\
\hline LDL-c/HDL-c ratio & 46 & $4.17 \pm 1.22$ & 2 & 3.9 & 7.7 \\
\hline
\end{tabular}




\begin{tabular}{|c|c|}
\hline Classification & Frequency $(\%)$ \\
\hline Normal & $27 \quad(29.6 \%)$ \\
\hline Overweight & $35(38.5 \%)$ \\
\hline Obesity class I & $25(27.5 \%)$ \\
\hline Obesity class II & $4 \quad(4.4 \%)$ \\
\hline Total & $91 \quad(100 \%)$ \\
\hline
\end{tabular}

values had $35.5 \mathrm{mg} / \mathrm{dL}$ more in the median triglyceride level than the other group did, and this difference was $19.0 \mathrm{mg} / \mathrm{dL}$ in the women and $64.5 \mathrm{mg} / \mathrm{dL}$ in the men.

Figure 1 compares the initial median BMI values and the serum lipids with the values obtained 3 months after dietary counseling. A significant reduction occurred in the BMI, total cholesterol, and LDL-c values $(p<0.01)$ and also in the triglyceride values $(\mathrm{p}<0.05)$. The median HDL-c value, which was within the normal range, was maintained, and no significant difference $(\mathrm{p}=0.78)$ occurred between the 2 screenings.

Table III shows the frequency of the individuals in each reference range of the serum lipids at the first and last screenings. A significant reduction ( $\mathrm{p}<0.01$ ) may be observed in the percentile of high cholesterol $(89.6 \%$ down to $47.9 \%)$, high and very high LDL-c ( $82.6 \%$ down to $45.7 \%)$, high and very high triglycerides ( $43.6 \%$ down to $16.7 \%$ ), and the cholesterol/HDL-c ratio of high risk (65.9\% down to $40.9 \%$ ). Yet a reduction is noticed in the low HDL-c (24.4\% down to $15.6 \%$ ) and the LDL-c/HDL-c ratio of high risk (81.3\% down to 56.3\%), although these results were not statistically significant.

\section{Discussion}

The higher percentage of women in this study may reflect a greater female demand for primary prevention services, because of their greater concern with their own health.

At the initial screening, by the inclusion criteria, the study population had high total cholesterol and LDL-c rates but adequate HDL-c levels. BMI was also high and the

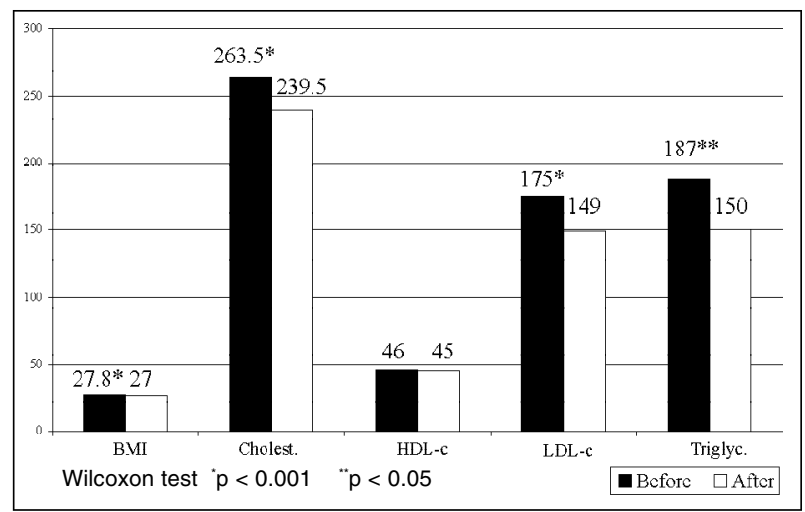

Fig. 1 - Comparison of the mean BMI and serum lipid values before and after 3 months of dietary intervention.

\begin{tabular}{|c|c|c|c|}
\hline \multicolumn{4}{|c|}{$\begin{array}{l}\text { Table III - Characterization of the lipid risk in hypercholesterolemic } \\
\text { patients before and after the dietary intervention, according to the } \\
\text { norm Atherosclerosis Prevention Guide of the Brazilian } \\
\text { Cardiology Society. }\end{array}$} \\
\hline \multirow[b]{2}{*}{ Lipids } & \multirow[b]{2}{*}{$\mathrm{N}$} & \multicolumn{2}{|c|}{ Frequency $(\%)$} \\
\hline & & $1^{\mathrm{a}}$ consultation & $\begin{array}{c}\text { last } \\
\text { consultation }\end{array}$ \\
\hline Total Cholesterol & 96 & & \\
\hline Optimuma & & 0 & 14.6 \\
\hline Boderline $^{b}$ & & 10.4 & 37.5 \\
\hline $\mathrm{High}^{\mathrm{c}}$ & & 89.6 & 47.9 \\
\hline LDL-c & 46 & & \\
\hline Optimum $^{d}$ & & 0 & 2.2 \\
\hline Desirable $e^{e}$ & & 2.2 & 19,5 \\
\hline Boderline $^{f}$ & & 15.2 & 32.6 \\
\hline High $^{\mathrm{g}}$ & & 47.8 & 26.2 \\
\hline Very high ${ }^{\mathrm{h}}$ & & 34.8 & 19.5 \\
\hline HDL-c & 45 & & \\
\hline Low $^{i}$ & & 24.4 & 15.6 \\
\hline Boderline $^{\mathrm{j}}$ & & 66.7 & 75.5 \\
\hline High $^{k}$ & & 8.9 & 8.9 \\
\hline Triglycerides & 78 & & \\
\hline Optimum¹ & & 41 & 50 \\
\hline Boderline $^{\mathrm{m}}$ & & 15.4 & 33.3 \\
\hline $\mathrm{High}^{\mathrm{n}}$ & & 41.0 & 16.7 \\
\hline Very high $^{0}$ & & 2.6 & 0 \\
\hline Cholesterol/ HDL ratio & 44 & & \\
\hline Low risk ${ }^{p}$ & & 13.6 & 31.8 \\
\hline Boderlineq & & 20.5 & 27.3 \\
\hline High risk ${ }^{r}$ & & 65.9 & 40.9 \\
\hline LDL/HDL ratio & 16 & & \\
\hline Low risk ${ }^{s}$ & & 6.2 & 6.2 \\
\hline Boderline $^{t}$ & & 12.5 & 37.5 \\
\hline High risk ${ }^{u}$ & & 81.3 & 56.3 \\
\hline $\begin{array}{l}\chi^{2} \text { Cholesterol }(\mathrm{a}+\mathrm{b} \mathrm{x} \mathrm{c}) \\
\mathrm{o})=13.43 \mathrm{p}=0.0002^{*} ; \chi^{2} \\
\text { Cholesterol/HDL-c ratio }( \\
1.11 \mathrm{p}=0.29 ; \chi^{2} \text { LDL-c/ }\end{array}$ & $\begin{array}{l}38.79 \\
\text { DL-c } \\
+\mathrm{q} x \\
\text { DL-c }\end{array}$ & $\begin{array}{l}.0001^{*} ; \chi^{2} \text { Triglyce } \\
+\mathrm{fxg}+\mathrm{h})=13.6 \\
53 \mathrm{p}=0.02^{*} ; \chi^{2} \mathrm{H} \\
+\mathrm{txu})=2.33 \mathrm{p}\end{array}$ & $\begin{array}{l}\text { des }(1+m \times n+ \\
p=0.0002^{*} ; \chi^{2} \\
-c(i \times j+k)= \\
0.13\end{array}$ \\
\hline
\end{tabular}

triglyceride levels had very differentiated values. Although the levels of HDL-c were adequate, high mean values were observed for the Castelli I and II indexes, and according to the Framingham study, a total cholesterol/HDL-c ratio greater than 5.0 compared with a ratio of 3.5 increases the risk of arteriosclerotic coronary disease 3 times in women ${ }^{17}$.

As for characterization of the nutritional status, it was found that less than a third of the patients had normal weight, and the majority was classified as overweight or obese. This fact reinforced the hypothesis of several researchers, who have suggested that excess weight is frequently associated with lipid alterations ${ }^{18}$ and also contributes to the risk of coronary disease. Kuczmarski et al ${ }^{11}$ defined BMI > 27 as an independent risk factor for coronary disease for both sexes.

When the characterization of lipid risk for cardiovascular diseases was analyzed, it was observed that $100 \%$ and 98\% had levels above the desirable values for total cholesterol and LDL-c, respectively, when they entered the health service. Most of the patients were borderline or high risk by the Castellli I and II indexes, and according to the Framingham study, the total cholesterol/HDL-c ratio identified the population at greatest risk among the women ${ }^{17}$. 
It was further observed that almost half the patients concomitantly had high risk for triglycerides, which may be directly related to the high prevalence of overweight and obesity in this group.

Denke et $\mathrm{al}^{19}$ researched American women and observed that higher BMI values were associated with triglyceride levels of 35 to $48 \mathrm{mg} / \mathrm{dL}$ higher and HDL-c levels of 5 to $9 \mathrm{mg} / \mathrm{dL}$ lower. In the present study, obese individuals (BMI $>27$ ) also had greater triglyceride values, and the difference was more accentuated in the men. Regarding the HDL-c levels, no difference was found for BMI, which coincides with the initial characterization of risk for HDL-c where the majority had low risk even in the presence of high, frequent obesity and overweight.

In the first 3 months (second screening) after the dietary intervention, significant improvement occurred in the lipid profile of the patients, because a fall occurred in the total cholesterol, LDL-c, and triglyceride levels, but the HDL-c levels, which were already adequate were not altered. In this period, the dietary guidance given had also reduced the BMI, which may have contributed to the reduction in triglyceride levels.

Ciorlia ${ }^{8}$ studied a group of electricians with borderline and high serum cholesterol who received dietary counseling and observed a similar result for total serum cholesterol reduction after 8 years. In this study, the author also observed in the same time interval increased cholesterol levels in those who had previously desirable cholesterol levels, but who did not receive dietary guidance, showing that without preventative measures the cholesterol tended to increase with age ${ }^{8}$.

Controlled studies of dietary or medical intervention in hypercholesterolemic men without coronary disease showed that a mean reduction of $10 \%$ in total cholesterol for 4 or 5 years resulted in a $26 \%$ lower frequency of coronary events than that observed in controls ${ }^{6}$.

In the present study, the median reduction in total cholesterol and LDL-c was $9.1 \%$ and $14.9 \%$, respectively. It is an expressive reduction, mainly when the hypothesis is considered that many of these patients had dyslipidemia that was more difficult to control (possibly genetic) once they were referred by other health professionals who had detected this difficulty.

When comparing the reference ranges for serum lipids, before and after dietary intervention, a considerable increase is observed in frequency of the individuals with optimum and borderline cholesterol, the desirable and borderline LDL-c, and the optimum and borderline triglycerides. At the same time, a decrease occurs in the number of patients with high cholesterol, high and very high LDL-c, and high triglycerides. Thus, these results show an important reduction in the number of people with higher levels of serum lipids (high and very high), a fact that could represent a reduction in costs in primary prevention, since it may result in a decreased need for lipid-lowering medication, which is responsible for $90 \%$ of the total treatment cost ${ }^{12}$.

In conclusion, this study reinforced the recommendation that the first conduct to be adopted in hypercholesterolemia treatment is dietary intervention, because this provides significant improvement in the lipid profile of patients. However, the study also showed that some of the patients did not manage to reach desirable total cholesterol or LDL-c levels, therefore help from lipid-lowering therapy should be more accessible to the low income population.

\section{References}

1. Ministério da Saúde - Brasil. Coordenação de Doenças Cardiovasculares no Brasil: Sistema Único de Saúde. Brasília, 1993.

2. Castelli WP. Epidemiology of coronary heart disease: the Framingham study. Am J Med 1984; 27: 4-12.

3. Steinberg D. Lipoprotein and pathogenesis of atherosclerosis. Circulation 1987; 79: 508-14.

4. Lólio CA, Souza JMP, Laurenti R. Declínio da mortalidade por doenças cardiovasculares no município de São Paulo, Brasil, no período de 1970 a 1983. Rev Saúde Públ S Paulo 1986; 20: 454-64.

5. Vartiainen E, Puska $P$, Jousilahti $P$, et al. Twenty-year trends in coronary risk factors in North Karelia and in other áreas of Finland. Int J Epidemiol 1994; 23: 495-504.

6. $2^{\circ}$ Consenso Brasileiro sobre Dislipidemias. Avaliação, detecção e tratamento. Arq Bras Cardiol 1996; 67: 109-27.

7. Sempos CT, Cleeman JI, Carrol MD, etal. Prevalence of high blood cholesterol among US adults: an up date based on guidelines from the second report of the National Cholesterol Education Program Adult Treatmet Panel. JAMA 1993; 269: 3009-14.

8. Ciórlia LAS. Intervenção dietética e níveis de colesterol plasmático em grupo de eletricitários. Arq Bras Cardiol 1997; 68.

9. National Cholesterol Education Program: Second Report of the Expert Panel on Detection, Evaluation, and Treatment of High Blood Cholesterol in Adults (ATP-11). NIH Publication n 93-3095, 1993.

10. World Health Organization. Preventing and managing the global epidemic: report of a WHO Consultation on Obesity. Geneva, 1997; 3-5.
11. Kuczmarski RJ, Flegal KM, Campbell SM, Johnson CL. Increasing prevalence of overweight among US adults: the National Health and Nutrition Examination Surveys, 1960 to 1991 . JAMA 1994; 272: 205-11.

12. III Diretrizes Brasileiras sobre Dislipidemias e Diretriz de Prevenção da Aterosclerose do Departamento de Aterosclerose da Sociedade Brasileira de Cardiologia. Arq Bras Cardiol 2001; 77 (supl III): 1-48.

13. Novazzi JP, Rabelo LM, Vale AAL, Pinto LESA, Martinez TLR. Conduta clínica no paciente dislipidêmico. In: Martinez TLR. Condutas Clínicas nas Dislipidemias. Belo Horizonte: Ed. Saúde:, 1997: 119-137.

14. Castelli WP, Abbot WD, Mc Namara PM. Summary estimates of cholesterol used to predict coronary heart disease. Circulation 1983; 67: 730-4.

15. Centers for Disease Control \& Prevention (CDC) - Epi-info, version 6: a word processing, database, and statistics program for Public Health. Geneva, WHO, 1997.

16. Fox E, Kuo J, Tilling L, Ulrich C. - User's manual - Sigma Stat: statistical software for windows. Germany: Jandel, 1994.

17. Martinez TLR, Rabelo LM, Barros MAV, Cendoroglo MS, Aldrighi JM. Dislipidemias em mulheres. In: Martinez TLR. Condutas Clínicas nas Dislipidemias. Belo Horizonte: Ed. Saúde, 1997: 215-28.

18. Araújo LMB. Dislipidemias e obesidade. In: Martinez TLR. Condutas Clínicas nas Dislipidemias. Belo Horizonte: Ed. Saúde, 1997: 261-7.

19. Denke MA, Sempos CT, Grundy SM. Excess body weight. An under-recognized contributor to dyslipidemia in white American women. Arch Intern Med 1994; 154: 401-10. 